\title{
COMPARING DIFFERENT TYPES OF PROFESSIONAL PRACTITIONER ENGAGEMENT IN AN INTEGRATED DESIGN ENGINEERING DEGREE
}

\author{
Ioannis GEORGILAS, Elies DEKONINCK, Vimal DHOKIA, Joseph FLYNN, Edward ELIAS \\ Department of Mechanical Engineering, University of Bath, United Kingdom
}

\begin{abstract}
Design engineering education needs to be close to industrial practice, since industry is the final destination of most graduates. For this reason, early engagement with 'real' practitioners can be beneficial to educational outcomes. Although much research has been done comparing the skills and approaches of engineering design students and professional practitioners little research to date has looked in detail how this engagement affects the educational process. In this study, we evaluate the impact professional practitioners had on the learning process and the delivery of learning outcomes for a number of units in a specific Integrated Design Engineering (IDE) course. We are reporting data collected by three data sources, feedback from the cohort via surveys of "Start, Stop, Continue" that run at the end of each unit; the official feedback survey of the university; and focus group feedback. Our key findings are that the students appreciate the real design context and passionate engagement the professional practitioner $(\mathrm{PP})$ can offer, when immersed in the teaching process and setting the assignment, but also are critical of the negative effects the PP can have in terms of marking assessments or limiting the creative potential of open-ended projects.
\end{abstract}

Keywords: Professional practitioners, engineering design, studio-based projects, learning outcomes

\section{INTRODUCTION}

Design engineering education is a process that needs to happen in close collaboration with industry, since the latter is the final destination of most graduates in their professional life. For this reason, early engagement with 'real' practitioners is crucial to benefit educational outcomes. Much research has been done comparing the skills and approaches of engineering design students and professional practitioners, (e.g. [1] and [2]). Some previous work [3] has investigated the value of using practitioner engagement to review and update curriculum content. However, little research to date has looked in detail at how professional practitioner engagement affects the educational process and outcomes. With the current work we are attempting to fill this gap. We evaluate the impact professional practitioners had on the learning process and the delivery of learning outcomes for a number of units in a specific Integrated Design Engineering (IDE) course.

The IDE course we are investigating is a collaboration between Departments of Mechanical Engineering (MechEng) and Electrical and Electronic Engineering (EEEng) aiming to create multidisciplinary design engineers of the future. Students from both departments can join after two years of discipline specific studies (MechEng or EEEng) and then complete two years to attain and MEng in IDE. As part of the latter two years there are five mandatory Design-Make-Test (D-M-T) units. The units are run in a short, intensive fashion (4 weeks duration) with coursework-only assessment in team-based open-ended project work. In the vision for the creation of the course, much inspiration came from our own Department of Architecture. In architecture education, the engagement of professional practitioners is common for studio-based units. Their education approach has been studied. For example, Schön [4] developed the concept of the 'reflective practitioner' by studying - amongst others - professional architects and he later translated his concepts of professional competence into important advice for teaching and learning [5]. 
This study is trying to capture the impact of the professional practitioners (PP) via reporting data on the student's opinions - collected via a number of sources - as well as the teaching team's reflection upon improving the teaching environment.

\section{RESEARCH METHODS}

In this study information for the five (D-M-T) units of the IDE programme have been compared. The five units offer a broad spectrum of professional practitioner engagement, from none, to the practitioners developing, delivering and assessing elements of the unit. Table 1 summarises the units and years of study and the level of involvement of the practitioners.

Table 1. IDE Unit names, year of study, and professional practitioner Involvement (PPI)

\begin{tabular}{|c|c|c|c|c|c|}
\hline Unit Name & $\begin{array}{c}\text { User Centred } \\
\text { Design }\end{array}$ & $\begin{array}{c}\text { Mechatronic } \\
\text { Design Proj. I }\end{array}$ & $\begin{array}{c}\text { Reverse } \\
\text { Engineering }\end{array}$ & $\begin{array}{c}\text { Mechatronic } \\
\text { Design Proj. II }\end{array}$ & $\begin{array}{c}\text { Design } \\
\text { Optimisation }\end{array}$ \\
\hline Year of Study & 3 & 3 & 3 & 4 & 4 \\
\hline PPI & High & Low & Medium-High & None & Medium \\
\hline
\end{tabular}

In order to ensure that the data between units were comparable the feedback came from the same cohort of students - 16 in number. The cohort attended all the unit during the last two years of their studies towards their MEng degree.

The study used 3 types of data: the anonymous feedback from the cohort via surveys of "Start, Stop, Continue" (SSC) that run at the end of each unit; the official feedback survey of the university (quantitative and qualitative) collected at the end of each semester; and focus group feedback collected at the end of the fourth year of studies. The data has been collected in a common format that best captured the impact the professional practitioner had. A number of quotes where selected to highlight the views of the students and detailed rationale for the involvement and format of the professional practitioners' engagement for each unit are given.

\section{RESULTS}

In this section specific findings for the different units will be given. Each unit will be addressed individually, and a summative table of common finding will be reported at the end.

\subsection{User Centred Design}

The primary plan for the professional practitioner was to provide real industrial engagement in the form of a real project assignment. The aim was to demonstrate the use of User Centred Design (UCD) principles within a real context and for the core principles to be delivered by designers and engineers who practice it on a daily basis. PPs from the company were involved from the get-go. They helped to create the unit syllabus, assignments and various delivery mechanisms. They also provided support in the weekly presentation sessions by marking and providing oral feedback. Moreover, the PP's company liaised with real users and provided contact time and opportunities to engage and further investigate their need.

Based on the student feedback it was gleaned that the unit provided a very interesting insight into an applied design process and engaging with a real company was good. Getting hands on experience with real people, both the PPs and the users made the design process more engaging. The unit enabled the students to gain real world design experience (facilitated by the company). Working with the company was an excellent experience and provided real and genuine context to a design exercise. This in conjunction with the users enabled a progressive and insightful view of the design process with the students commenting that "I loved working with [the company] because they were actually in the middle of the project..." and "I think [the company delivered the best PP engagement] ... because they made you do something that you could apply in industry."

Regarding the involvement with assessment, in the last (major) presentation new people from the company were involved. The students felt that this was unfair as they were not involved in the earlier presentations or unit in general. "... there were a lot of new people watching the final presentation and we had actually done several presentations already in the run-up... What was actually done to make sure that they knew what we were doing? We also don't want to have to repeat ourselves, we just want to talk about the new things we have done." 
Overall it was felt by some that the company was interested in the project and so it improved the engagement process commenting that "it should be directly linked... To be directly relevant to the course.... On a physical level... To the assessment.... To what we're doing... That's why think UCD works so well because they were so interested... It was totally what they did..." This reinforced the intention that the involvement of the professional practitioner can be truly transformative to a unit. It has enabled the students to engage with real world problems and challenges that the company undertake on a daily basis.

\subsection{Mechatronic Design Project I}

This unit was designed to offer to the students an initial understanding of designing and building systems that efficiently combine mechanical hardware, electronics, and software. The unit immerses the students into this method of design and building with a group-based project-only coursework that has to be completed on a tight timeline ( 3 weeks) assessed via presentations and demonstrations. The envisioned role of the PP was to provide first-hand experience with mechatronic system development. In a lecture and workshop the PP presents their professional practice and gives design examples in specific products which are intended to inspire the students and help them realise the context of the unit. Moreover, it was envisioned that the PP would offer advice and recommendations for the specific design solutions that the students would have prepared by that time and also assist in the presentations as a panel member.

The students assessed the role of the PP positively and as an inspiration. Specifically, they noted that “... [the PP's] lecture was really interesting and gave an inspiring example application [for mechatronics]." This indicates that the role of the PP helped the students to establish the context of the unit and reflect on how the learning outcomes relate to industrial reality. On the other hand, a different group of students considered the PP as a potential source of new or more content for the unit. Specifically, they noted that "...[the] lecture was interesting, but no new knowledge gained...". The students' suggestion can be seen as utilitarian, i.e. to gain direct knowledge that can contribute to the content of the unit: something that was not the intention of the involvement of the PP in this unit.

Regarding modes of engagement, the workshop content was deemed irrelevant to the coursework of the students and some students suggested it should be removed, "...I enjoyed seeing the [design paradigms/systems] and how they worked. Maybe remove the workshop part." Moreover, the students felt that the engagement of the PP should have been earlier in the unit as noted in "... [the PP's session] was good, but maybe sooner [closer] to the start of mechatronics? Not in 2nd week." and "...[the PP's session] was really interesting but it would've been more engaging earlier on in the project as an intro when we were less pressed for time...". In other words, they wanted to have an earlier engagement with the PP to effectively immerse their content in the unit. Finally, when the PP participated in the assessment process the staff observed that the PP assigned a much wider range of marks than the academic members in their marks for one specific criterion, namely presentation style. Although this has not been discussed with the PP it is assumed that this was caused by the PP and academics having different expectations for presenting technical information

\subsection{Reverse Engineering}

The unit looked to immerse the students in the practical considerations of product design, manufacture and costing. For this aim, the students were divided into groups and each group given a different product to investigate, dismantle, analyse and redesign. All the products were provided by the same company and three PPs were involved from that company. The involvement of the PPs was dictated largely by their work schedule. They were not able to attend the start and so the unit convenor was briefed on details and some non-obvious issues with their products, as well as useful information such as weekly manufacturing quantities and pricing data. Moreover, the PPs would review the student work at the end of the two-week period. Bringing their first-hand experience and privileged behind the scenes knowledge to assess whether the student had made realistic conclusions from their analysis.

The role of the PP and the use of real products was to firmly ground the course in real world problems, with all the associated technical but also commercial challenges that come with that. The students appreciated this straight away noting that "One of the most interesting and useful aspects were the constant linking to industry practices to understand how it fits in with their business strategy." Moreover "One of the main appeals for me was that it seemed like this information regarding industry practice for innovation, was coming from practical experience and that it would be very useful in future." and the students pointed that "There were good links to industry which made the projects even 
more relevant and the presentation to the company gave a good insight into how they use reverse engineering".

Regarding assessment involvement, the PPs joined an academic assessment panel for formal marking of the projects but led the conversation in terms of questioning the students. It was thought that the PPs scoring may be variable due to them not having realistic expectations or having a desire to be encouraging rather than too judgemental. However, the results seemed to correlate well with those of the university staff and this was perhaps helped by 2 of the 3 PPs being university alumni who were familiar with the department's practices. Some students suggested they would even have liked more feedback from the company: "It would be good at the end of the presentations to get verbal feedback from them... Because that's the thing that we missed out on... When [the company] came they asked us questions, but they didn't say "yes this was good, but this could be different" and that would be a useful industry link."

From the feedback the students also reported a transformative effect from the engagement of the PPs. Specifically, they reported that "It was particularly rewarding to have [company] staff visit" It left the students with a highly memorable experience commenting that "I loved the module" and "Overall the [unit] was very successful in giving us the tools to use a new design approach in real life scenarios"

\subsection{Mechatronic Design Project II}

The unit Mechatronic Design Project II is different than the rest used in this study since the decision was taken to not involve a professional practitioner. The reason has been that the intended Learning Outcomes of the unit where designed to be aimed at the higher levels of the revisited Bloom's Taxonomy of Learning [6]. This meant that the students are going to synthesise and design complex systems within broad design specifications with open-ended elements to encourage creativity and lateral thinking. To this end the involvement of the PP might have hindered this process by narrowing the scope of the design question.

Despite the fact that specific feedback was not requested by the students with respect to PP involvement for this units, during the focus groups the students volunteered their view which was summarised as "... I liked Mechatronics 2 this year, because "the event" could be whatever you wanted. I think if you bring a practitioner in they will be like "we want you to solve this [specific] problem."

\subsection{Design Optimisation Project}

This unit teaches students a variety of numerical and experimental approaches to design optimisation. Although the unit makes use of lectures, the majority of the learning outcomes rely on a problem-based learning approach. The aim is for students to understand and deploy sensitivity analysis, design of experiments, linear programming and gradient-based optimisation approaches (or other iterative approaches). Wind turbines are used as a common theme to bring all of these facets together within a single, coherent project. The involvement of PPs is limited to one workshop, spanning an entire afternoon. This workshop was used to introduce the students to the concept of generative design (GD) and allow them to explore this approach to design optimisation via a dedicated software package. This software also combines several of the techniques that are taught during this unit. The workshop was intended to help students understand the links and interplay between different techniques and broaden their horizons within the scope of design optimisation.

There are two themes of note in the responses. Firstly, evidence suggests that students enjoyed the workshop, finding it "interesting and definitely worthwhile". One student highlighted that it gave a "good insight" in to the wider context of design optimisation. The same student also reflected positively on the use of additional non-assessed material. Secondly, opinion was divided in terms of how useful this particular workshop format was. One student stated that it "felt relevant not to the coursework but to the general theme of the course, [it's] nice to do things that explore the scope of the project and aren't just focused purely on coursework". Conversely, two comments clearly focus on the fact that the workshop was not related to the assessment: "the Generative Design [...] didn't impact our projects...' and "if we had been able to use the software [in our projects], that would have been useful". This combination of views suggests that the workshop itself was well received. However, because there was not an obvious connection with one of the assessments, some students did not see the immediate value. One interpretation of the comments is that students do not always assign value to additional unassessed content within the syllabus. At this stage, there is insufficient evidence to quantify how transformative the involvement of the PP was. However, as with other units within the programme, the language used 
Table 2. Themes presented across Units

\begin{tabular}{|c|c|c|c|c|c|}
\hline Theme & $\begin{array}{c}\text { User Centred } \\
\text { Design }\end{array}$ & $\begin{array}{c}\text { Mechatronic } \\
\text { Design Proj. I }\end{array}$ & $\begin{array}{c}\text { Reverse } \\
\text { Engineering }\end{array}$ & $\begin{array}{c}\text { Mechatronic } \\
\text { Design Proj. II }\end{array}$ & $\begin{array}{c}\text { Design } \\
\text { Optimisation }\end{array}$ \\
\hline $\begin{array}{c}\text { Provide realistic } \\
\text { context of unit }\end{array}$ & $\checkmark$ & $\checkmark$ & $\checkmark$ & - & $\checkmark$ \\
\hline $\begin{array}{c}\text { Provide feedback } \\
\text { and advice }\end{array}$ & $\checkmark$ & $\checkmark$ & - & - & - \\
\hline $\begin{array}{c}\text { Insight into real } \\
\text { design process }\end{array}$ & $\checkmark$ & $(\checkmark)^{1}$ & $\checkmark$ & - & $\checkmark$ \\
\hline $\begin{array}{c}\text { PP's effect on } \\
\text { project or assessment }\end{array}$ & $\checkmark$ & $\checkmark$ & - & $\checkmark^{2}$ & $\checkmark$ \\
$\begin{array}{c}\text { Inspiring } \\
\text { Engagement }\end{array}$ & $\checkmark$ & $\checkmark$ & $\checkmark$ & - & $\checkmark$ \\
\hline \multicolumn{7}{l}{ 'Negative feedback added to importance of this. ${ }^{2}$ No PP in this unit but student concern captured. } \\
\hline
\end{tabular}

in relation to the PP workshop was in line with the intentions set out in the design of the unit. Specific examples include: "really enjoyed the [company] talk [... Generative Design] is the cutting edge of what's going to happen". This gives a nice supporting example of one student's horizons being broadened through the involvement of the PP.

\section{DISCUSSION}

A number of common themes were identified across all units, summarised in Table 2. Firstly, the PP added to the realism of the units' engineering context. This was part of the aim for the PP involvement in the units and the students did indeed identify it. Next was the students' needs to make sure the PP's engage with the projects at hand by providing feedback and advice on the specific concepts, proposals or designs. Thirdly, the potential for PPs to offer insights into real design processes and new knowledge was recognised. When this was not achieved, or the knowledge was deemed irrelevant, the students did highlight it. In most of the units, there were concerns with PPs ability to fairly contribute to summative assessments and the potential of them limiting design freedom in units if setting the design assignment. Finally, on the units that had PPs involved there has been evidence that this involvement has been inspiring to the students. This latest finding has been a positive result with regards to the planning and preparation of the involvement of PPs in this course. Students appreciated PP contribution even in cases where the feedback has been negative with regards to the content of the engagement but the context has been received positively, as captured by the wording this is expressed.

\section{CONCLUSIONS}

This study aims to investigate the effect professional practitioners can have in the teaching of engineering design. Specifically, we report on the impact PP had on the learning process and the delivery from the students' perspective. The study compares first-hand information and views of students collected via anonymous feedback and focus groups for five units that are part of the curriculum of an Integrated Design Engineering degree. The key findings are that the students appreciate the real design context and the passionate engagement the PPs can offer, when immersed in the teaching process, but they are also critical of the negative effects PPs can have when marking assessments or limiting the creative potential of open-ended projects something that can be facilitated if the remit of the PP's engagement is defined clearly when briefing them, to protect creativity. Unlike Gunaratne in [7] we reported no significant difference in motivation or drive of our students in our units due to PPs. Our students already feel driven not let down their team mates and are highly competitive within the class (the studio environment means they are highly aware of what their peers are doing). Although there are limitations to this work, namely the inevitable difference between the units in terms of learning objectives, this work is a first step towards identifying the key elements for successfully integrating PPs in design engineering teaching practice. A further experimental study with control conditions to assess the degrees of impact of PPs' involvement can maximise the benefits for the students and the learning process. 


\section{REFERENCES}

[1] Atman C.J., Adams R.S., Cardella M.E., Turns J., Mosborg S. and Saleem J. 2007. Engineering design processes: A comparison of students and expert practitioners. Journal of engineering Education, 96(4), pp.359-379.

[2] Cash P.J., Hicks B.J. and Culley S.J., 2012. A comparison of the behaviour of student engineers and professional engineers when designing. In DS 70: Proceedings of DESIGN 2012, the 12th International Design Conference, Dubrovnik, Croatia (pp. 757-766).

[3] Knox R.C., Sabatini D.A., Sack R.L., Haskins R.D., Roach L.W. and Fairbairn S.W. (1995). A Practitioner-Educator Partnership for Teaching Engineering Design. Journal of Engineering Education, 84(1), 5-11.

[4] Schön D. (1983). The reflective practitioner: How professionals think in action. New York: Basic Books.

[5] Schön D. (1987). Educating the reflective practitioner: Towards a new design for teaching and learning in the professions (The Jossey-Bass higher education series). San Francisco, Calif.: Jossey-Bass.

[6] Anderson L.W., Krathwohl D.R., Airasian P.W., Cruikshank K.A., Mayer R.E., Pintrich P.R. and Wittrock M.C. 2001. A taxonomy for learning, teaching, and assessing: A revision of Bloom's taxonomy of educational objectives, abridged edition. White Plains, NY: Longman.

[7] Gunaratne M. 1995. Integrating professional experience in geotechnical class designs. Journal of Engineering Education, 84(2), 117-119. 